\title{
Performance of Grid-Connected Variable Speed WECS Using PMSG under MTPA Control with Common Synchronizing Circuit \\ ${ }^{* 1}$ Dhanashree K. Porate, ${ }^{2}$ S. P. Gawande, ${ }^{3}$ K. B. Porate, ${ }^{4}$ J. A. Sheikh \\ ${ }^{1,3}$ Priyadarshini College of Engineering, Nagpur \\ ${ }^{2,4}$ Yeshwantrao Chavan College of Engineering, Nagpur \\ Email: 1dhanashreeporate8@gmail.com, ${ }^{2}$ spgawande_18@yahoo.com, ${ }^{3}$ kporate@yahoo.com, 4jawedshaikh01@yahoo.co.in
}

Received: 06th October 2019, Accepted: 20th November 2019, Published: 31st December 2019

\begin{abstract}
This paper exclusively evaluates the performance of grid connected variable speed Wind Energy Conversion System (WECS) using Permanent Magnet Synchronous Generator (PMSG) with Maximum Torque Per Ampere (MTPA) control. A new approach is employed using common synchronising circuit for generator and grid-side converters. The back-to-back converters used in WECS are realized using conventional two-level converters with common DC-link. In MTPA control maximum power is extracted using Optimal Power Control (OPC) approach. The standard and modified space vector representation under separate and common synchronization conditions are also derived for the proposed control and its improvisation is discussed. A detailed system performance has been evaluated and compared for this control and effective analysis has been carried out and presented with experimental results.
\end{abstract}

Keywords

Wind Energy, Conversion System, Synchronous Generator

\section{Introduction}

Wind energy is one of the most prominently used renewable energy source due to its rapid growth. The base energy generated by the WECS is nearly equal to that of any other conventional plants. [1]-[3]. Generally, WECS can be extracted in two ways which are fixed speed and variable speed. In WECS with fixed speed, the system operates at a constant speed which is dependent on the choice of turbine and the generator. Due to the unpredictability of speed of the wind, it is beneficial to realize variable speed WECS [4], [5]. In variable speed WECS, generators operating for various speeds such as Doubly Fed Induction Generator (DFIG), wound rotor or PMSG are used [6]. Amongst all, permanent magnet synchronous generator is the widely used for WECS. PMSG with poles in higher number is usually used and could operate at lower speeds to synchronize with the turbine [7]-[8]. Further PMSG do not require any DC supply for excitation purpose and also slip rings and brushes are removed. The generator is finally connected with the power grid using the converters which are fully controlled working on Pulse Width Modulation (PWM). The gear box in PMSG is optional. Therefore, the use of PMSG seems more advantageous for variable speed WECS using appropriate MPPT control technique.

The control schemes in WECS are implemented for controlling the generator-side as well as grid-side converter. The converter control of generator-side is implemented for controlling the active power and the converter control of grid-side for maintaining the DC-link voltage [9], [10]. The grid-side control is usually common for all the generators. Amongst the existing controls for generator-side converter, ZDC, UPF and MTPA control schemes are most popular and regularly used techniques out of which MTPA control is significantly used because of its easy implementation. The main feature of the MTPA scheme is that it produces required torque with a minimum amount of stator current. This results in increase of utilization of the stator current and the losses dissipated in the stator are reduced. However, when such controls are applied, separate synchronisation is needed for both generator and grid-side control. The inclusion of two different phase-lock loops (PLL) increases control complexities and creates difficulties in synchronisation.

To avoid these issues, this paper proposes MTPA control with common synchronisation circuit. The detailed performance of WECS using PMSG has been demonstrated under this approach evaluating the control scheme and improvisation in the system performance with the help of modified space vector diagrams. The simulation results are also validated using experimentation.

Variable Speed Wind Energy Conversion System with MTPA Control

The permanent magnet synchronous generators are preferable for WECS as it can be designed with a higher poles for lower speeds as comparable to that of the turbine speed. The use of PMSG also provides full controllability of the system for maximum wind power extraction and grid interface. Therefore, the efficiency and reliability of VSC-based PMSG wind turbine is assessed to be higher than that of any other wind turbine. In case of WECS the converters are essential because the generator produces the voltage with variable frequency which has to be transformed to match the grid voltage which will be constant. Using PMSG, the variable speed wind turbine can be implemented for various converter configurations such as back-to-back voltage source 
converter topology, current source converter topology, DC-DC converter topology and also for parallel converters topology. In study system back-to-back voltage source converters are used and realized using Insulated Gate Bi-polar Transistor (IGBT).

As shown in the Fig. 1, Voltage Source Rectifier (VSR) is governed by MTPA control along with its MPPT technique. The Voltage Source Inverter (VSI) is operated using the grid-side control. Filters (LC) are used across the converters and grid to smoothen the voltage waveforms. This paper suggests MTPA control with common synchronising circuits for variable speed WECS using PMSG. In MTPA control, the stator current need to be transformed into $d$-axis and $q$-axis components. The generator torque referred as electromagnetic torque can be given as,

$T_{e}=\frac{3}{2} P\left(\lambda I_{q s}-\left(L_{d}-L_{q}\right) I_{d s} I_{q s}\right.$

Equation (1) indicates that generator can produce any given torque with distinct values of $d$-axis stator current $I_{d s}$ and $q$-axis stator current $I_{q s}$. The $d$-axis stator current $I_{d s}$ is considered to be the flux producing component and $q$-axis stator current $I_{q s}$ is the torque producing component. Thus, it is able to produce given torque with minimum stator current by balancing the ratio of $I_{d s}$ and $I_{q s}$. Stator current can be resolved and implies that, $I_{d s}=\sqrt{I_{s}^{2}-I_{q s}^{2}}$

Substituting equation (2) in equation (1) the electromagnetic torque becomes,

$T_{e}=\frac{3}{2} P\left(\lambda I_{q s}-\left(L_{d}-L_{q}\right)\left(\sqrt{I_{s}^{2}-I_{q s}^{2}}\right) I_{q s}\right)$

Now considering non-salient pole, differentiating equation (3) with respect to $I_{q s}$ and then equating to zero for MTPA control. Solving it $I_{d s}$ can be found out to be,

$$
I_{d s}=\frac{\lambda}{2\left(L_{d}-L_{q}\right)} \pm \sqrt{\frac{\lambda^{2}}{4\left(L_{d}-L_{q}\right)}+I_{q s}^{2}}
$$

As for MTPA control, magnitude of $d$-axis stator current $I_{d s}$ should be minimized, therefore, positive sign is selected which is shown in equation (5). As stator inductance of $d$-axis $L_{d}$ is usually less than stator inductance of $q$-axis $L_{d}$ in PMSG, their difference will come out to be negative. This will result in minimal $I_{d s}$.

$$
I_{d s}=\frac{\lambda}{2\left(L_{d}-L_{q}\right)}+\sqrt{\frac{\lambda^{2}}{4\left(L_{d}-L_{q}\right)}+I_{q s}^{2}}
$$

As seen in Fig. 1, rotor speed controller is the main part of this control. The $d$-axis voltage $V_{d s}$ and $q$-axis voltage $V_{q s}$ and currents $I_{d s}$ and $I_{q s}$ are given to mechanical power $P_{m}$ calculator through low pass filter (LPF).

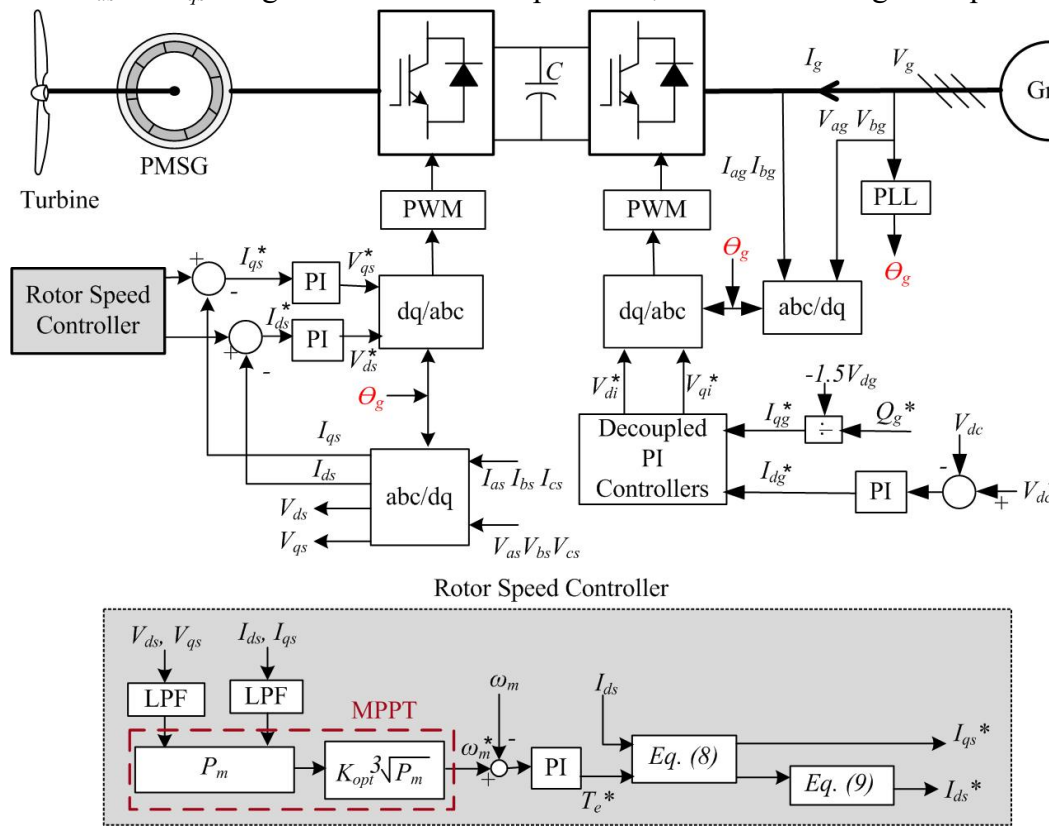

Fig. 1: MTPA Control Scheme With Common Synchronizing Circuit

The $P_{m}$ calculator means the MPPT scheme which can be achieved in different methods by tracking the $P_{m}$ and speed $\omega_{m}$ of the turbine. The MPPT schemes are usually incorporated into the power converters. In this 
particular control while realizing MTPA control, maximum power is extracted with the help of optimal power control (OPC). In OPC, mechanical power $P_{m}$ should be measured from the generator as illustrated in Fig. 1 in highlighted red block. This power $P_{m}$ will be required to obtain the rotor speed reference $\omega_{m}{ }^{*}$ for realizing the MPPT operation. The reference of rotor speed $\omega_{m}{ }^{*}$ is obtained by using (6),

$\omega_{m}^{*}=K_{\text {opt }} \sqrt[3]{P_{m}}$

where $K_{\text {opt }}$ is the coefficient which can be defined by the rated parameters of the generator. This rotor speed reference $\omega_{m}{ }^{*}$ is further used in MTPA control technique. By using the equation (5), $P_{m}$ will be generated, which is necessary for the MPPT control technique.

$P_{m}=\frac{3}{2}\left(v_{d s} I_{d s}+v_{q s} I_{q s}\right)+\frac{3}{2}\left(I_{s}\right)^{2} R_{s}$

where $R_{s}$ is stator resistance and $I_{s}$ can be given as in equation (7). The speed $\omega_{m}$ and its reference $\omega_{m}{ }^{*}$ are compared with the PI controller which will generate reference torque $T_{e}{ }^{*}$. The reference torque $T_{e}{ }^{*}$ will be required for calculation of $d$-axis stator current reference $I_{d s}{ }^{*}$ and $q$-axis stator current reference $I_{q s}{ }^{*}$ as follows,

$$
I_{q s}^{*}=\frac{2 T_{e}^{*}}{3 P\left(\lambda-\left(L_{d}-L_{q}\right)\right) I_{d s}} \quad \& \quad I_{d s}^{*}=\frac{\lambda}{2\left(L_{d}-L_{q}\right)}+\sqrt{\frac{\lambda^{2}}{4\left(L_{d}-L_{q}\right)+\left(I_{q s}^{*}\right)^{2}}}
$$

These reference currents will now be compared with the actual $d$-axis stator current $I_{d s}$ and $q$-axis stator current $I_{q s}$ which are generated by using the $a b c-d q$ transformation. The actual and reference currents are compared with the help of PI controllers. This gives the voltage references for $d$-axis $V_{d s}{ }^{*}$ and q-axis $V_{q s}{ }^{*}$ which are transformed into $a b c$ frame of voltages. The MTPA control is provided with the common synchronizing circuit by using the same grid voltage angle $\theta_{g}$ in generator side as well as the grid-side convertor control. Also, practically generator-side converter can be provided with a synchronising circuit based on the generator phase voltages with frequency bandwidth limit of $10 \mathrm{~Hz}(50 \mathrm{~Hz}-60 \mathrm{~Hz})$. Hence, considering these control flexibilities the generator with frequency around $53 \mathrm{~Hz}$ can be synchronized with the grid of frequency $50 \mathrm{~Hz}$ using common synchronizing circuit. This helps in efficient and simpler grid synchronization. The switching pulses will be generated using these voltages for the generator-side converter with pulse width modulation (PWM).

The grid-side control mainly focuses on regulating the voltage of DC link $V_{d c}$. The grid-side voltages $V_{a g}, V_{b g}$, $V_{c g}$ and currents $I_{a g}, I_{b g}, I_{c g}$ are used for overall realization of grid-side control. The $V_{d c}$ is also maintained using grid side control. The $d$-axis and $q$-axis reference voltages $V_{d g}\left(V_{c g}=0\right)$ and currents $I_{d g}$ and $I_{q g}$ are formed by using $a b c-d q$ transformation. Hence, as seen in figure, $V_{d i}{ }^{*} \& V_{q i}{ }^{*}$ are generated which undergo $d q$ - $a b c$ transformation to generate the reference signals. The three-phase references $V_{a i}{ }^{*}, V_{b i}{ }^{*}, V_{c i}{ }^{*}$ are obtained and are given to PWM control to generate the switching sequence for grid-side inverter.

\section{Result Analysis}

The systems in Fig. 1 is implemented in MATLAB using parameters mentioned in Table 1. The time of simulating the system is considered to be $1 \mathrm{sec}$. The characteristics of turbine and changes in wind speed are shown in Fig. 2. The changes in wind speed are found to be from 0 to $12 \mathrm{~m} / \mathrm{sec}$ at $0.2 \mathrm{sec}$ as in Fig. $2 a$. The corresponding characteristics of turbine can be depicted in Fig. $2 b$. The maximum power at base wind speed is $0.8 \mathrm{pu}$. Fig. $2 c$ shows the stator currents $I_{a s}, I_{b s}, I_{c s}$ for the MTPA control strategy. As speed of the wind changes at $0.2 \mathrm{sec}$., the stator current tends to become stable after the speed change.

As per MTPA methodology, the value of stator current required to generate same amount of torque which proves the feasibility of the MTPA control. The speed of the generator is depicted in Fig. $2 d$. The generator speed is seen to be almost constant throughout the performance after the speed change at instance of 0.2 sec. The comparison of electromagnetic torque $T_{e}$ and mechanical torque $T_{m}$ is illustrated in Fig. $2 e$. Both the torques following each other shows the effective operation of generator connected in the WECS.

Fig. $3 a$ shows the DC-link voltage $V_{d c}$ from which it implies that the voltage is regulated at constant level after there is change in speed at $0.2 \mathrm{sec}$. The DC link voltage is maintained to its reference value showing suitable performance of grid-side inverter. Fig. $3 \mathrm{~b}$ shows the currents of grid $I_{a g}, I_{b g}, I_{c g}$ and the corresponding voltages $V_{a g}, V_{b g}, V_{c g}$ which validated the grid voltage mentioned in the simulation parameters can be clearly shown in Fig. $3 c$. The active and reactive powers are attained as illustrated in Fig. $3 d$ indicating that the power is supplied to the grid as both the powers are negative.

Improvisation of Space Vector Representation Using Proposed Synchronising Schemes

Under a separate synchronising circuit, the standard mathematical model and vector diagram representation of PMSG under MTPA control are shown in Fig. 4. Fig. $4 a$ shows the space vector representation where rotor flux $\lambda$ is aligned with $d$-axis and all the vectors rotate at synchronous speed $\omega_{r}$. Stator current $I_{s}$ is shown as the result of vector addition of $I_{d s}$ and $I_{q s}$ and similarly stator voltage $V_{s}$ is shown as the result of vector addition of $d$-axis voltage $V_{d s}$ and $q$-axis stator voltage $V_{q s}$. 
The stator current vector angle $\delta$ with respect to $q$-axis is given as,

$\delta=\tan ^{-1} \frac{I_{d s}}{I_{q s}}=\frac{\pi}{2}-\theta_{i}$

Fig. $4 b, c$ shows the mathematical modelling of PMSG for $d$-axis and $q$-axis respectively where the stator resistance $R_{s}$ is considered nearly to be zero. The voltages for $d$-axis and $q$-axis are applied and the corresponding currents are flowing through the circuit as seen in Fig $4 a$.

The steady state operating condition of PMSG obtained from the actual simulation and its corresponding vector diagram using MTPA control is illustrated in Fig $4 d$, e.

\begin{tabular}{|l|l|l|l|l|l|}
\hline \multicolumn{2}{|c|}{ Generator Parameters } & \multicolumn{2}{c|}{ Turbine parameters } & \multicolumn{2}{c|}{ Other system parameters } \\
\hline Parameters & Values & Parameters & Values & Parameters & Values \\
\hline Rating $\left(P_{g}\right)$ & $1.5 \mathrm{~kW}$ & Power rating $\left(P_{t}\right)$ & $10.5 \mathrm{~kW}$ & System frequency $(f)$ & $50 \mathrm{~Hz}$ \\
\hline Pole pairs $(P)$ & 30 & Base wind speed $(v)$ & $12 \mathrm{~m} / \mathrm{sec}$ & DC link capacitor $(C)$ & $2000 \mu \mathrm{F}$ \\
\hline Nominal speed $\left(\omega_{r}\right)$ & $100 \mathrm{rpm}$ & Pitch angle $(\beta)$ & $0 \mathrm{deg}$ & Inverter switching frequency $\left(f_{s}\right)$ & $1 \mathrm{kHz}$ \\
\hline Stator resistance $\left(R_{s}\right)$ & $0.425 \mathrm{ohm}$ & & & Filter inductance $\left(L_{f}\right)$ & $20 \mathrm{mH}$ \\
\hline Inductance $\left(L_{d}\right)$ & $0.0082 \mathrm{H}$ & & & Filter capacitance $\left(C_{f}\right)$ & $40 \mu \mathrm{F}$ \\
\hline Inductance $\left(L_{q}\right)$ & $0.0082 \mathrm{H}$ & & & 3 phase load voltage $\left(V_{L}\right)$ & $230 \mathrm{~V}$ \\
\hline Inertia & $\begin{array}{l}0.01197 \mathrm{Kg} \\
\mathbf{m}^{2}\end{array}$ & & & Grid voltage $\left(V_{g}\right)$ & $230 \mathrm{~V}$ \\
& & & & \\
\hline
\end{tabular}

Table 1: System Parameters
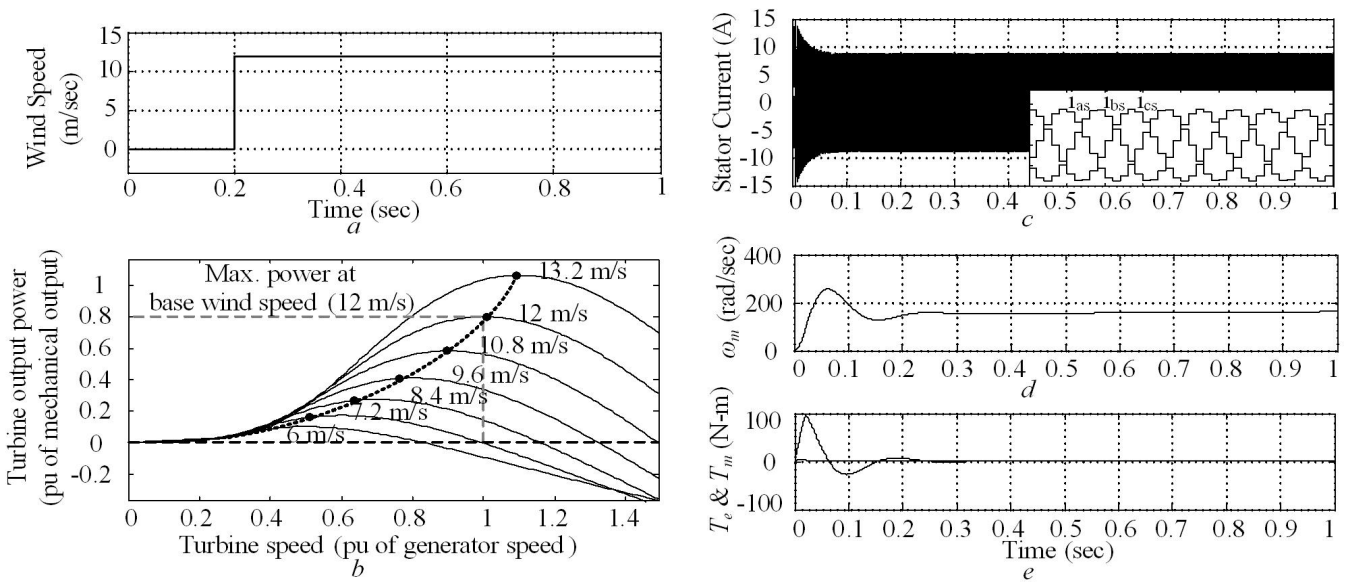

Fig. 2: Generator Results

(a) Wind Speed Changes (b) Characteristics of Turbine (c) Three Phase Stator Current (d) Rotor Speed (e) Electromagnetic and Mechanical Torque
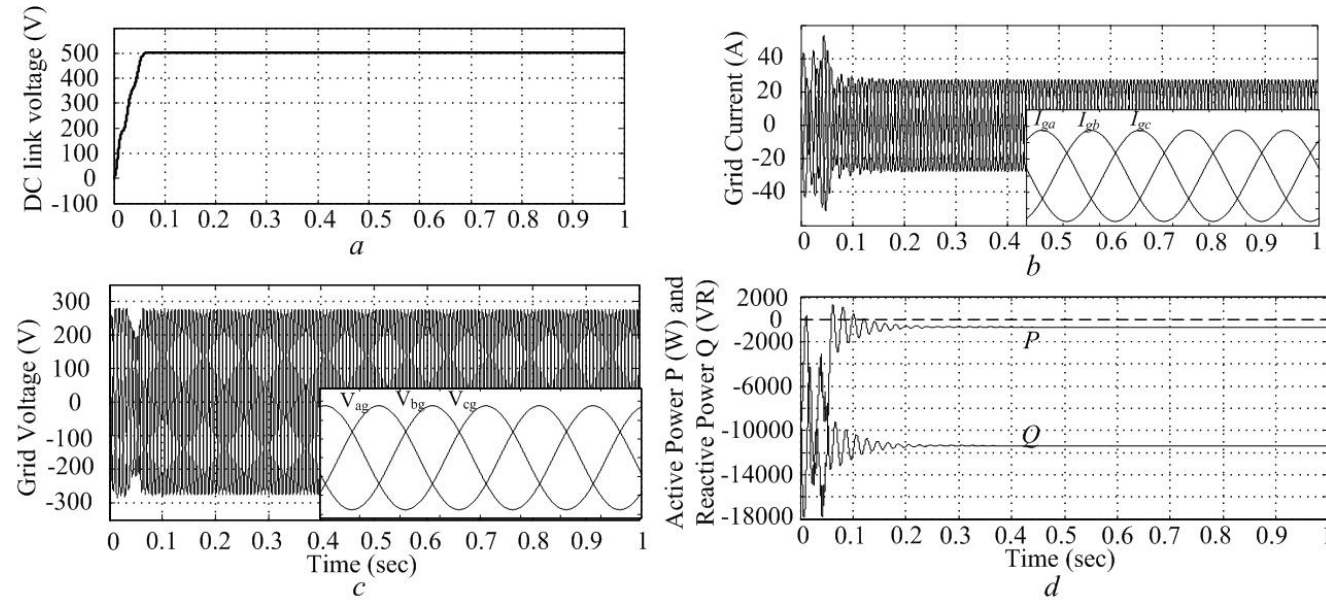

Fig. 3: Grid and Inverter Results

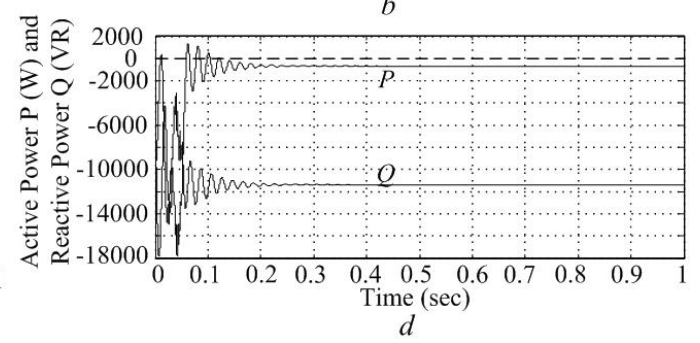

(a)Voltage of DC-Link (b) Grid Currents (c) Grid Voltages (d) Active and Reactive Power 

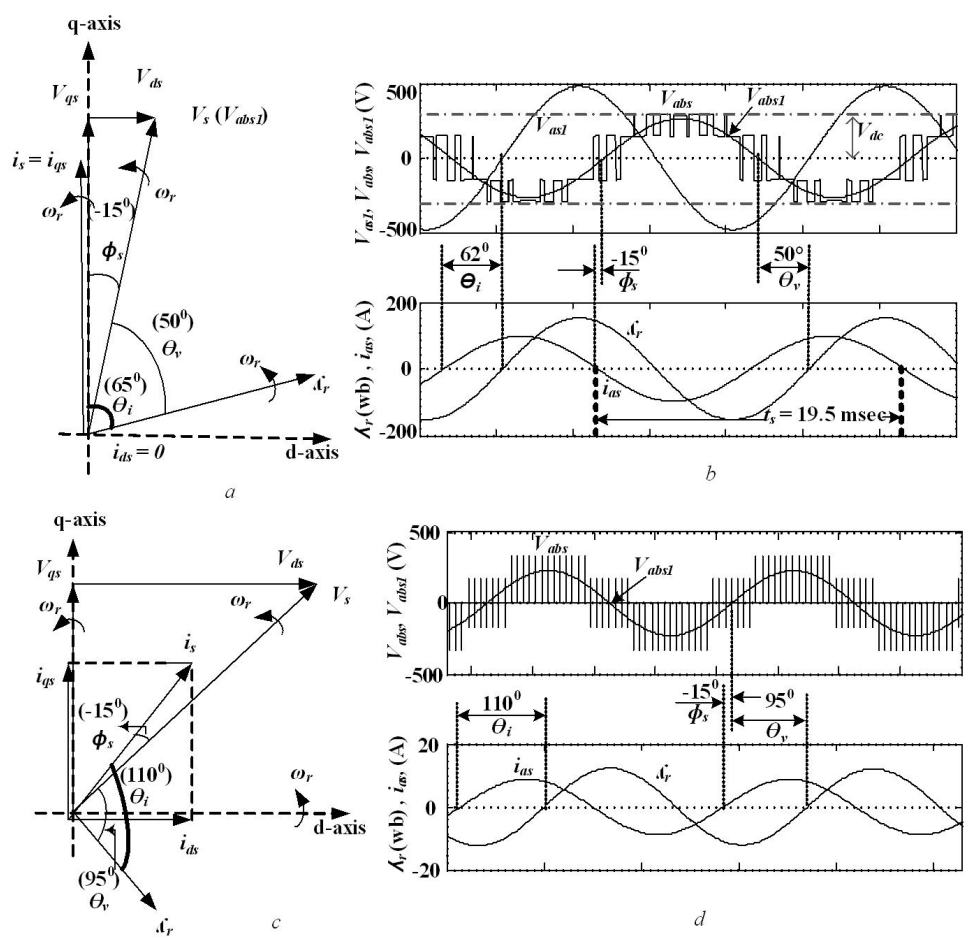

Fig.4: Mathematical and Vector Representation

(a)Vector Representation for MTPA Control (b) Mathematical Modelling for PMSG of d-axis (c) Mathematical Modelling for PMSG of q-axis (d) Modified Space Vector Diagram for MTPA Control (e) Modified Steady State System Waveforms with MTPA Control

Since a two-level converter is used, the device and converter switching frequency can be maintained equal (1 $\mathrm{KHz}$ ). The $d-q$ axis inductance of generator, use of PWM and filter helps to maintain nearly sinusoidal stator current. The stator current angle $\theta_{i}\left(110^{\circ}\right)$, stator voltage angle $\theta_{v}\left(95^{\circ}\right)$ and power factor angle $\varphi_{s}\left(-15^{0}\right)$ are also shown in steady state waveform and phasor diagram. From Fig. $4 d$ it is clear that due to common synchronising circuit, $\lambda$ is not aligned on $d$-axis because of which the stator power factor angle reduces.

Furthermore, it is to be noted that in MTPA control $\varphi_{s}$ is contributed by angle between $I_{s}=\sqrt{I_{d s}^{2}+I_{q s}^{2}}$ (with $I_{q s}$ $=I_{d s}$ ) and $V_{a b s}$, with $\lambda$ away from $V_{a b s l}$. It is effectively seen that the control provide satisfactory performance with $\varphi_{s}=-15^{0}$.

\section{Experimental Results}

The experimental setup of PMSG based WECS is fabricated with the back-to-back converters as shown in Fig. 5 $a$. The 5 blade horizontal axis wind turbine is used. The turbine consists of an inbuilt PMSG having rating $24 \mathrm{~V}$, $200 \mathrm{~W}$. The wind turbine is rotated with the help of variable speed exhaust fan which rotates the shaft of the inbuilt PMSG. Both the converters at generator as well as grid-side are two-level three phase converters realized using MOSFET (IRF P460) rated 500V, 20A. MOSFET is a controlled switch which generates the pulses with the help of a control. The implementation of control for the switch is carried out using a microcontroller dsPIC33EP256MC202 which is a 16 bit, 28 pin, 2 port IC. This IC can be used up to $120 \mathrm{KHz}$ frequency. It needs an input supply of range $3 \mathrm{~V}$ to $3.6 \mathrm{~V}$ to produce pulses for the converter. The pulses are generated using a programming language and is transferred to the microcontroller IC using a pickit. For close loop control of WECS hall effect voltage sensor LV 25p and current sensors LA 25p are used which can sense the voltage from $10 \mathrm{~V}$ to $500 \mathrm{~V}$ and current up to $10 \mathrm{~A}$. The sensed voltage is given to the controller for further execution. Using an isolation transformer $(3-18 \mathrm{~V})$ this system is connected with the grid through resistive load of $100 \mathrm{ohms}, 5 \mathrm{~A}$. The results are captured in Digital Signal Oscilloscope (DSO) with rating of $200 \mathrm{MHz}, 2 \mathrm{Gs} / \mathrm{sec}$. The output of PMSG which is three phase is seen in Fig. $5 \mathrm{~b}$. The expected sinusoidal waveform for $V_{s a}, V_{s b}, V_{s c}$ can be seen. The corresponding phase voltages $V_{p a}, V_{p b}, V_{p c}$ of three phase converter with phase-a current for resistive load is depicted in Fig. 5 c. Fig. $5 d$ gives the current and voltage waveform of converter when connected to grid with proposed control. The in-phase waveforms shows the unity power factor operation at converter end. In fig. $5 e$ various waveforms phase-a at grid side are shown. $V_{g}$ is indicated as phase-a voltage of the grid and $V_{i n v}$ is 
inverter voltage of phase-a. The phase-a grid current is indicated by $I_{g}$. The waveforms for grid voltage and current are in phase indicating the unity power factor operation at grid side representing that the active power $P$ is flowing to the grid.
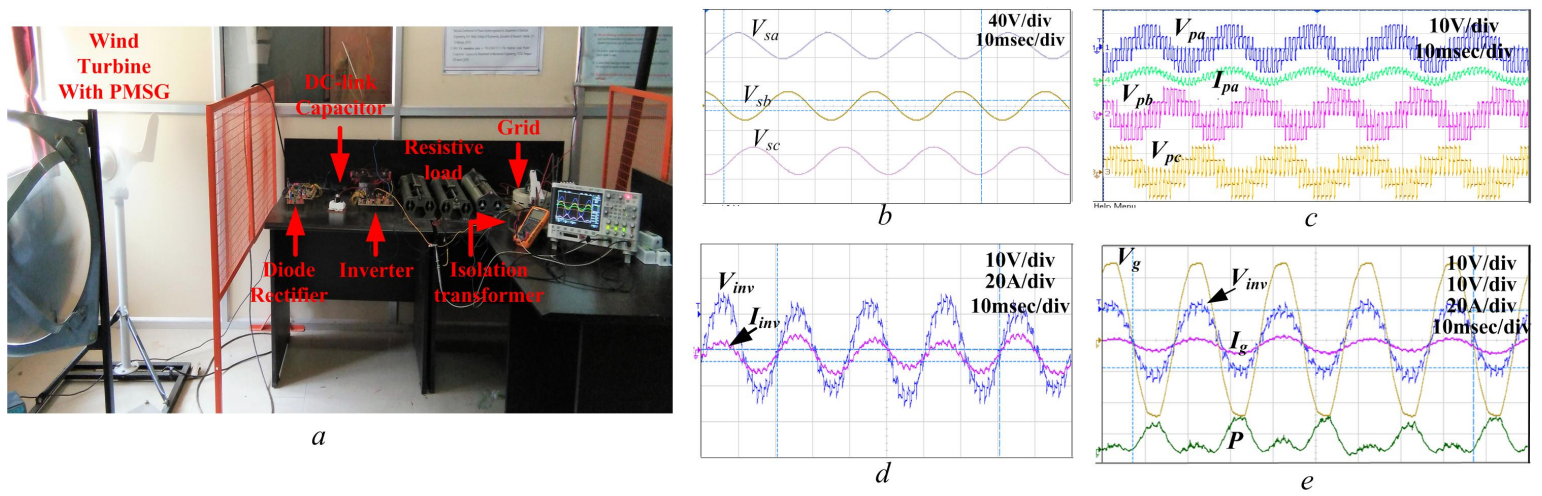

Fig. 5: (a) Experimental Setup (b) Generator Voltages (c) Phase Voltages of Three-Phase Inverter with Phase-a Current (d) Voltage and Current of Inverter for Phase-a (e) Inverter Voltage, Grid Voltage, Grid Current and Power.

\section{Conclusion}

In this paper, the PMSG based variable speed WECS for variable speed with common synchronising circuits is implemented. The modelling and vector diagrams of both the schemes with MPPT controls are explained in detail. Further, the modified space vector diagram and its corresponding steady state performances under common synchronising circuits for MTPA control has been drawn and compared with conventional phasors. Also, the improved system performance under new control has been elaborated and presented. This control scheme can be helpful in extracting the maximum power from the system at different wind speeds and successfully injects the generated power into the grid with successful operation. The proposed scheme is also validated through appropriate experimental results.

\section{References}

1. Reddy, T., Mishra, M., Srinivas, S. 2012. IEEE International Conference on Power Electronics, Drives and Energy systems. Synchronization of Variable Speed PMSG Based Wind Energy Conversion System to the Grid with Power Quality Improvement Features.

2. Wu, B., Lang, Y., Zargari, N., Kouro, S. 2011. A John Wiley \& Sons inc. publication. Power Conversion and Control of Wind Energy Systems. IEEE Press.

3. Porate D. K., Gawande S. P., Munshi A. P., Porate K. B., Kadwane S. G., Waghmare M. A. 2017. Elesvier Energy Procedia. Zero Direct-axis Current (ZDC) Control for Variable Speed Wind Energy Conversion System using PMSG. 117C: 943-950.

4. Porate D. K., Gawande S. P., Porate K. B.,Nagpure R. N., Waghmare M. A., Kadwane S. G., 2018. IEEE Conference on Power Electronics, Drives and Energy Systems (PEDES18). Performance of PMSG Based Variable Speed WECS with Parallel Back-to-Back Converters Using Separate Zero $d$-axis Current Control.

5. Hussain, J., Mishra, M. 2016. IEEE Transactions on Energy Conversion. Adaptive Maximum Power Point Tracking Control Algorithm for Wind Energy Conversion Systems. 31 (2):697-705.

6. Chinchilla, M., Arnaltes, S., Burgos, J. 2006. IEEE Transactions on Energy Conversion. Control of Permanent-Magnet Generators Applied to Variable-Speed Wind-Energy Systems Connected to the Grid. 21 (1):130-135.

7. Haque, M., Negnevitsky, M., Muttaqi, K. 2010. IEEE transactions on industry applications. A Novel Control Strategy for a Variable-Speed Wind Turbine with a Permanent-Magnet Synchronous Generator. 46 (1):331339.

8. Mendis N, Muttaqi KM, Sayeef Saad, Perera S.: 'Standalone operation of wind turbine-based variable speed generators with maximum power extraction capability'. IEEE Transaction on Energy Conversion 2012;27 (4),pp. 822-834.

9. Kouro S, Malinowski M, Gopakumar K, Pou J, Franquelo LG, Wu B, Rodriguez J, Perez M, and Leon JI. 2010. IEEE Trans. Ind. Electron. Recent advances and industrial applications of multilevel converters. 57: 2553-2580.

10. Blaabjerg F, Teodorescu R, Liserre M, Timbus AV. 2006. Industrial Electronics, IEEE Transactions. Overview of Control and Grid Synchronization for Distributed Power Generation Systems. 53:1398-1409. 